\title{
CORROSĀO EM ESTRUTURA DE CONCRETO ARMADO OCASIONADA PELA AÇĀO DE FERTILIZANTE E AMBIENTE MARÍTIMO.
}

\author{
SILVA, GERALDO MAGELA DA. \\ Engenheiro Civil \\ Universidade Federal de Ouro Preto \\ Minas Gerais; Brasil \\ geraldomsilva@gmail.com
}

\author{
RIBAS, ROVÁDAVIA ALINE DE JESUS \\ Engenheira Civil \\ Universidade Federal de Ouro Preto \\ Minas Gerais; Brasil \\ roviaaline@gmail.com
}

\section{RESUMO}

A corrosão é o fenômeno patológico mais comum no aço, modifica suas propriedades como a resistência mecânica, podendo comprometer a edificação. Esse fenômeno acelera-se quando as estruturas estão sujeitas à ação de substâncias e ambientes agressivos. Nesse contexto, este artigo objetiva analisar a ação da corrosão química/eletroquímica em uma estrutura de concreto armado de uma edificação, localizada em ambiente marítimo e em contato direto com fertilizantes e névoa marítima. Por meio de análise de laudos de perícia técnica e estudo de caso, apresenta-se o estado corrosivo das estruturas definindo os tipos e o grau de intensidade da corrosão dos elementos estruturais, que pode causar a diminuição do pH e a abertura de fissuras, levando à deterioração do concreto e corrosão da armadura, diminuindo sua vida útil. Procura-se entender o processo de formação da corrosão e a interação com o aço e o concreto, mostrando as soluções adotadas para evitar a ruína das estruturas.

Palavras-chave: corrosão, manifestação patológica, deterioração, estruturas.

\section{ABSTRACT}

Corrosion is the most common pathological phenomenon in steel, changing its properties as mechanical resistance, which can compromise the building. This phenomenon accelerated when the structures are subject to the actions of substances and aggressive environments. In this context, this article aims to analyze a chemical corrosion / electrochemical action in a reinforced concrete structure of a building, located in the maritime environment and in direct contact with fertilizers and sea fog. Through the analysis of the praises of the technical expertise and the case study, the corrosive state of the structures that define the types and the degree of corrosion intensity of the elements that can cause the $\mathrm{pH}$ and the crack opening, causing deterioration of the concrete, is presented and corrosion of the armature, reducing its useful life. Try to understand the process of corrosion training and interaction with steel and concrete, showing how the solutions adopted to avoid a ruin of the structures.

Keywords: corrosion, pathological manifestation, deterioration, structures.

\section{INTRODUÇÃO}

A corrosão tem como definição a deterioração de material, geralmente metálico, através de uma ação química ou eletroquímica do meio ambiente aliada ou não a esforços mecânicos. Essa deterioração representa alterações indesejáveis no material, como por exemplo, o desgaste, variações químicas e modificações estruturais, que o torna inadequado para o uso. Sendo a corrosão, em geral, um processo espontâneo, ela está constantemente transformando os materiais metálicos de modo que a durabilidade e desempenho dos mesmos deixam de satisfazer os fins a que se destinam (GENTIL, 2007).

Segundo Cândido (2005), a corrosão é o fenômeno patológico de ocorrência mais comum, que acomete principalmente metais ferrosos e não ferrosos, como zinco, manganês, alumínio, dentre outros. Ao atuar, essa manifestação patológica origina um elemento de características diferentes daquelas do material original, modificando algumas de suas propriedades, tais como resistência mecânica, elasticidade, ductilidade, estética etc, posto que o material resultante da corrosão (óxido ou hidróxido) não possui as mesmas características do material original, comprometendo a durabilidade da construção.

Os metais são geralmente encontrados na natureza como compostos, sendo comuns as ocorrências de óxidos e sulfetos metálicos. Os compostos que possuem conteúdo energético inferior aos dos metais são relativamente estáveis. Assim, os metais tendem a reagir de forma espontânea com os líquidos ou gases do meio ambiente em que são colocados, o ferro oxida (enferruja) ao ar e na água, e os objetos de prata escurecem expostos ao ar. O produto da corrosão de um metal é bem semelhante ao minério do qual é originalmente extraído. O óxido de ferro mais comumente encontrado na natureza é a hematita, $\mathrm{Fe}_{2} \mathrm{O}_{3}$, e a ferrugem é o $\mathrm{Fe}_{2} \mathrm{O}_{3}$ hidratado, $\mathrm{Fe}_{2} \mathrm{O}_{3} \cdot \mathrm{nH}_{2} \mathrm{O}$, isto é, o metal tendendo a retornar à sua condição de estabilidade (GENTIL, 2007). 


\subsection{Corrosão eletroquímica}

Dentro do contexto da corrosão das armaduras, há a necessidade de destinar atenção especial à agressividade do macroclima e microclima, haja vista que um dos ambientes de maior agressividade para o concreto armado é a atmosfera salina, principalmente pela ação da maresia, de águas saturadas de sais em contato direto com a estrutura ou névoa salina. Esses sais, tais como os de base cloreto, podem despassivar a armadura embutida no concreto e, assim, desencadear o processo de corrosão dos íons cloretos que penetram no concreto por meio de mecanismos de transporte de massa, tendo-se como exemplo a difusão iônica no concreto, até atingir a armadura. A corrosão de armaduras devida ao ingresso de cloretos é um dos problemas mais sérios e intensos que pode ocorrer em estruturas de concreto, podendo também provocar uma maior deterioração e refletir na limitação da vida útil de serviço (FERREIRA, 2003).

Segundo Helene (1982), o eletrólito é representado pela umidade presente no interior do concreto. A diferença de potencial entre dois pontos da superfície pode ocorrer por diversos fatores: por diferença de umidade, aeração, concentração salina, tensão no concreto e no aço, e falta de uniformidade na composição do aço.

De uma forma geral, à medida que os diversos tipos de corrosão vão se processando, os produtos decorrentes da corrosão eletroquímica do aço vão se acumulando cada vez mais ao redor das armaduras, criando verdadeiras "crostas" no seu entorno (CASCUDO, 1997). Por serem altamente expansivos, passam a ocupar volumes de 3 a 10 vezes superiores ao volume original do ferro, podendo causar pressões internas de expansão superiores a $15 \mathrm{MPa}$. Afirma também Cascudo (1997) que essas tensões internas são da ordem de $32 \mathrm{MPa}$, resultando em fissuração e facilitando ainda mais a entrada de agentes agressivos. Posterior à fissuração, pode ocorrer o destacamento da camada de cobrimento do concreto, deixando a armadura exposta (Figura 1), tamanha é a tensão expansiva exercida internamente pelos óxidos e hidróxidos de ferro gerados.
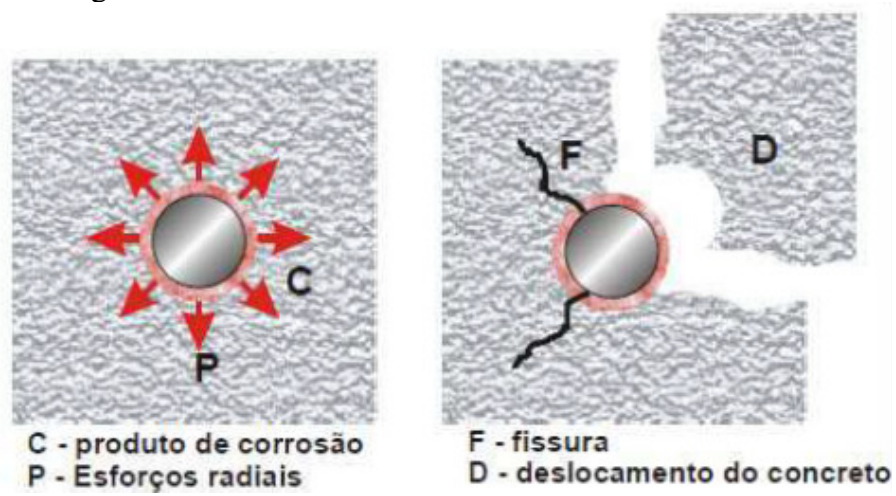

Figura 1: Esforços radicais produzidos que levam à fissuração e destacamento do concreto devido à corrosão das armaduras

Fonte: Cascudo, 1997.

A armadura de aço, ao corroer, perde seção na região anódica, devido à dissolução do ferro, resultando na perda da aderência aço/concreto, na redução da capacidade estrutural da peça e no surgimento de manchas de coloração marrom alaranjada (Figura 2).

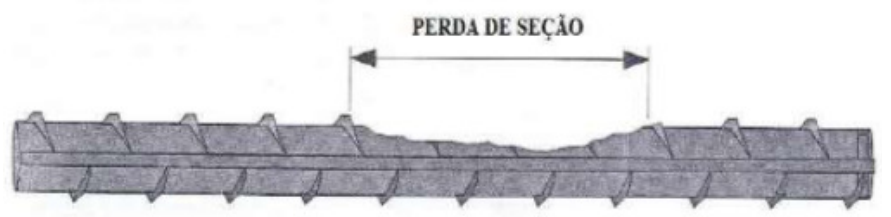

Figura 2: Perda de seção na barra de aço devido à corrosão eletroquímica Fonte: Cascudo, 1997.

Assim, devido às tensões internas expansivas provenientes dos produtos da corrosão (situados na região anódica), há a deterioração da armadura e o destacamento da camada de cobrimento, conforme Figura 3. 


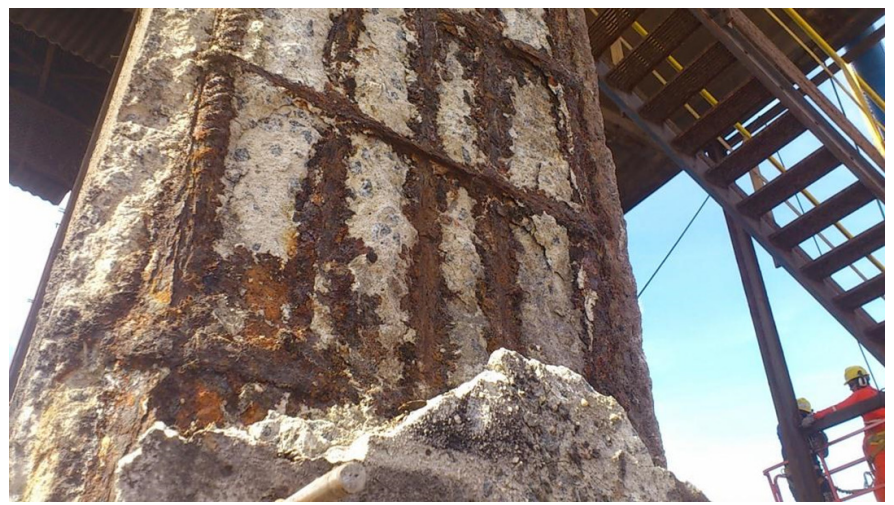

Figura 3: Desagregação de uma estrutura de concreto armado causada por ataque químico expansivo Fonte: Autor, 2015.

\subsection{Formas de corrosão}

A corrosão é um modo de destruição do metal, que se espalha pela sua superfície e além dela, ocorre em diferentes formas e pode ser classificada pela sua aparência ou forma de ataque. Assim, pode-se ter corrosão segundo: a morfologia, as causas ou mecanismos de formação, os fatores mecânicos, o meio corrosivo e a localização do ataque. A caracterização da forma da corrosão auxilia no esclarecimento do mecanismo e na aplicação de medidas de proteção (GENTIL, 2007). Segundo as diferentes formas de corrosão, tem-se:

- Uniforme: a corrosão se processa em toda a extensão da superfície, ocorrendo perda uniforme da espessura. É chamada de corrosão generalizada, mas essa terminologia não deve ser usada só para corrosão uniforme, pois pode-se ter corrosão por pite ou alveolar generalizada, ou seja, em toda a extensão da superfície corroída.

- Por placas: a corrosão se localiza em regiões da superfície metálica e não em toda sua extensão, formando placas com escavações.

- Alveolar: a corrosão se processa na superfície metálica produzindo sulcos ou escavações semelhantes a alvéolos apresentando fundo arredondado e profundidade geralmente menor do que seu diâmetro.

- Puntiforme ou por pite: a corrosão se processa em pontos ou em pequenas áreas localizadas na superfície metálica produzindo pites, que são cavidades que apresentam o fundo em forma angulosa e profundidade geralmente maior do que o seu diâmetro.

- Intragranular: esse tipo de corrosão se processa nos grãos cristalinos da rede cristalina do material metálico, o qual, pela perda de suas propriedades mecânicas, pode fraturar à menor solicitação mecânica, assim como no caso da corrosão intergranular, sendo que seus efeitos são muito mais catastróficos que no caso da corrosão intergranular.

- Intergranular: a corrosão se processa entre os grãos da rede cristalina do material metálico, o qual perde suas propriedades mecânicas e pode fraturar quando solicitado por esforços mecânicos, tendo-se então a corrosão sob tensão fraturante.

- Filiforme: a corrosão se processa sob a forma de finos filamentos, mas não profundos, que se propagam em diferentes direções e que não se ultrapassam, pois considera-se que o produto de corrosão apresenta carga positiva, daí a repulsão. Ocorre geralmente em superfícies metálicas revestidas com tintas ou com metais, ocasionando o deslocamento do revestimento.

- Empolamento pelo hidrogênio: o hidrogênio atômico penetra no material metálico e, como tem pequeno volume atômico, difunde-se rapidamente e, em regiões com descontinuidades, como inclusões e vazios, ele se transforma em hidrogênio molecular, $\mathrm{H}_{2}$, exercendo pressão e originando a formação de bolhas.

- Esfoliação: a corrosão se processa de forma paralela à superfície metálica. Ocorre em chapas ou componentes extrudados que tiveram seus grãos alongados e achatados, criando condições para que inclusões ou segregações, presentes no material, sejam transformadas, devido ao trabalho mecânico, em plaquetas alongadas.

- Em torno do cordão de solda: forma de corrosão que se observa em torno do cordão de solda, em aços inoxidáveis não estabilizados ou com teores de carbono maiores que $0,03 \%$, e a corrosão se processa intergranularmente.

\subsection{Mecanismos básicos da corrosão}

No estudo dos processos corrosivos devem ser sempre consideradas as variáveis dependentes do material metálico, do meio corrosivo e das condições operacionais, pois o estudo conjunto dessas variáveis permite indicar o material mais adequado para ser utilizado em determinados equipamentos ou instalações (GENTIL, 2007):

- Material metálico: composição química, presença de impurezas, processo de obtenção, tratamentos térmicos e mecânicos, estado da superfície, forma, união de materiais (solda, rebites etc) e contato com outros metais; 
- Meio corrosivo: composição química, concentração, impurezas, pH, temperatura, teor de oxigênio, pressão, sólidos suspensos;

- Condições operacionais: solicitações mecânicas, movimento relativo entre material metálico e meio, condições de imersão no meio (total ou parcial), meios de proteção contra a corrosão, operação contínua ou intermitente.

\subsection{Meios corrosivos}

Os meios corrosivos mais frequentes encontrados são atmosfera, águas naturais, solos, produtos químicos e, em menor escala, alimentos, substâncias fundidas, solventes orgânicos, madeiras e plásticos. A ação corrosiva da atmosfera depende dos seguintes fatores: substâncias poluentes (partículas sólidas e gases), temperatura, umidade relativa e tempo de permanência do filme de eletrólito na superfície metálica. É classificada em função da umidade na superfície metálica em seca, úmida e molhada (GENTIL, 2007). Algumas ponderações sobre os meios e sua influência nos processos corrosivos:

a) Umidade relativa: é dada pela relação entre o teor de vapor d'água encontrado no ar e o teor máximo que pode existir no mesmo. A influência da elevação da umidade na ação corrosiva da atmosfera é acentuada.

b) Corrosão atmosférica seca: ocorre em atmosfera isenta de umidade, sem qualquer presença de filme de eletrólito na superfície metálica; há oxidação lenta do metal e pouca formação do produto de corrosão e o mecanismo pode ser considerado químico.

c) Corrosão atmosférica úmida: ocorre em atmosferas com umidade relativa menor do que $100 \%$. Tem-se um fino filme de eletrólito depositado sobre a superfície metálica e a velocidade do processo corrosivo depende da umidade relativa, poluentes atmosféricos e higroscopicidade dos produtos de corrosão.

d) Corrosão atmosférica molhada: a umidade relativa é próxima a 100\% e ocorre condensação na superfície metálica, observando-se que a superfície fica molhada sob o eletrólito como, por exemplo, chuva e névoa salina depositadas nessa superfície metálica.

e) Partículas sólidas: as partículas sólidas, sob forma de poeiras, existem na atmosfera e a tornam mais corrosiva.

f) Gases: os gases mais frequentemente encontrados na atmosfera são: monóxido de carbono, dióxido de carbono, dióxido de enxofre, trióxido de enxofre, gás sulfídrico e amônia.

g) Temperatura: os efeitos da temperatura são vários e o processo corrosivo é mais rápido em temperaturas elevadas; mudanças de temperatura podem influenciar na solubilidade de produtos de corrosão, como é o caso dos carbonatos; gases são menos solúveis com a elevação da temperatura.

h) Águas naturais - Os materiais metálicos em contato com a água tendem a corroer e a corrosão depende de várias substâncias que podem contaminar a mesma; o caráter corrosivo da água também depende do $\mathrm{pH}$, da temperatura, da velocidade e da ação mecânica.

\section{OBJETIVOS}

Os objetivos desse trabalho são analisar a ação da corrosão química/eletroquímica em uma estrutura de concreto armado, localizada em um ambiente marítimo e em contato direto com fertilizantes, procurando-se entender seu processo de formação e sua interação com o aço e o concreto, e mostrar as soluções adotadas para controlar as manifestações patológicas e evitar que as estruturas da edificação atinjam seu estado limite último.

\section{METODOLOGIA}

A metodologia adotada é a pesquisa exploratória, realizada por meio de análise de laudo de perícia técnica e um estudo de caso, buscando-se entender o processo de corrosão de uma edificação, que possui estruturas de aço e de concreto armado, por meio de inspeção visual.

No estudo, apresenta-se o estado corrosivo das estruturas frente aos ataques de fertilizantes e névoa marítima, definindo-se os tipos e o grau de intensidade da corrosão dos elementos estruturais, que pode causar a diminuição do pH e a abertura de fissuras, levando à deterioração do concreto e corrosão da armadura e diminuindo sua vida útil.

\subsection{Caracterização do local}

Na Figura 4 apresenta-se um porto brasileiro inaugurado em 1966, que é o maior porto de exportação de minério de ferro do mundo e permite o acesso de navios graneleiros de grande porte. O clima do local é tropical, com temperatura média anual de $25{ }^{\circ} \mathrm{C}$ e umidade relativa do ar em torno de $77 \%$. Os terminais portuários dispõem de vários tipos de equipamentos também de grande porte para a movimentação e transporte de cargas em granel e atualmente operam com minério de ferro, pelotas, calcário, rocha fosfática, manganês, carvão, coque, antracito, soja, farelo de soja, milho, cloreto de potássio, ureia, enxofre, dentre outros.

Nesse porto está localizada a Torre de Fertilizantes FE-02, objeto de estudo deste trabalho (Figura 4). 


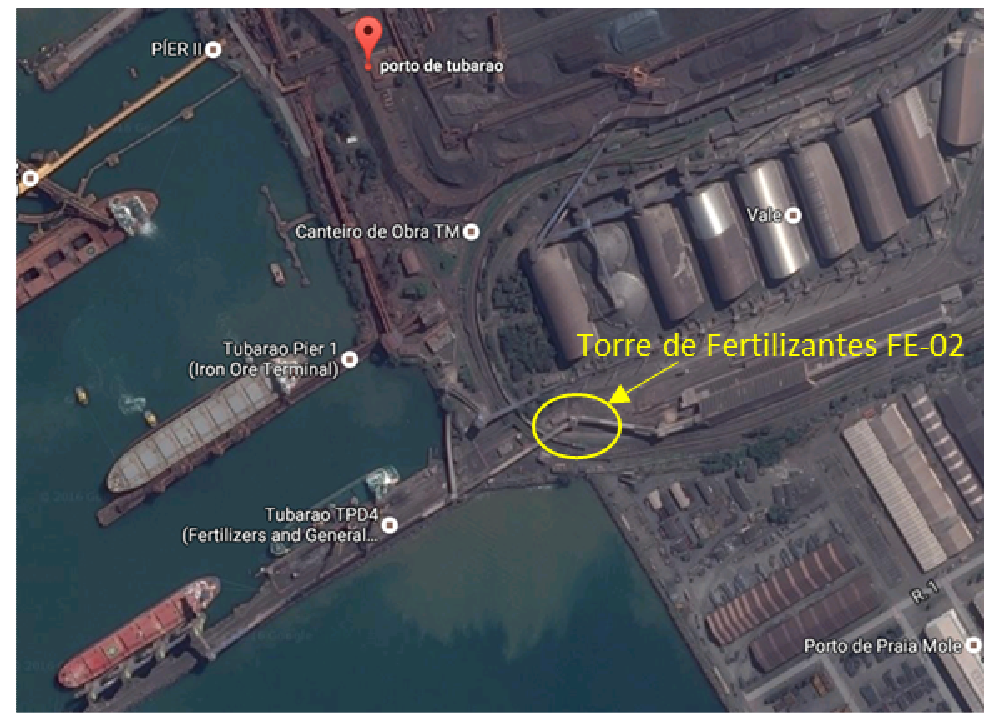

Figura 4: Terminal Portuário

\subsection{Caracterização do objeto estudado}

A Torre de Fertilizantes - FE-02 encontrava-se em processo avançado de deterioração devido à sua localização próxima à área marítima exposta à maresia e também devido ao transporte de fertilizantes entre os navios feito por meio de correias transportadores e torres até os galpões de estoque. Na Figura 5 apresenta-se a situação encontrada na área.

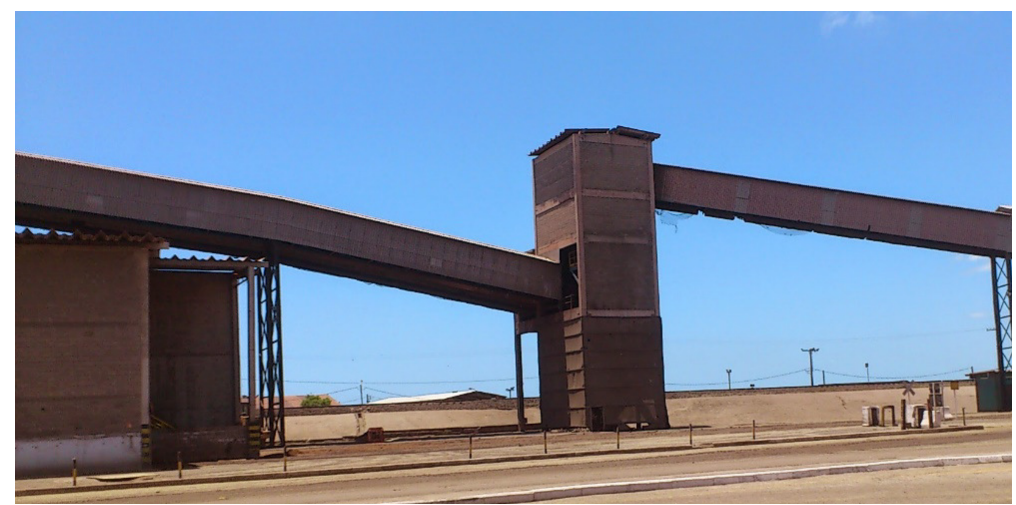

Figura 5: Torre de Transferência FE-02

Devido ao transporte de fertilizantes, por meio das correias, até os depósitos de estoque, os equipamentos estavam com considerável material acumulado (Figura 6).

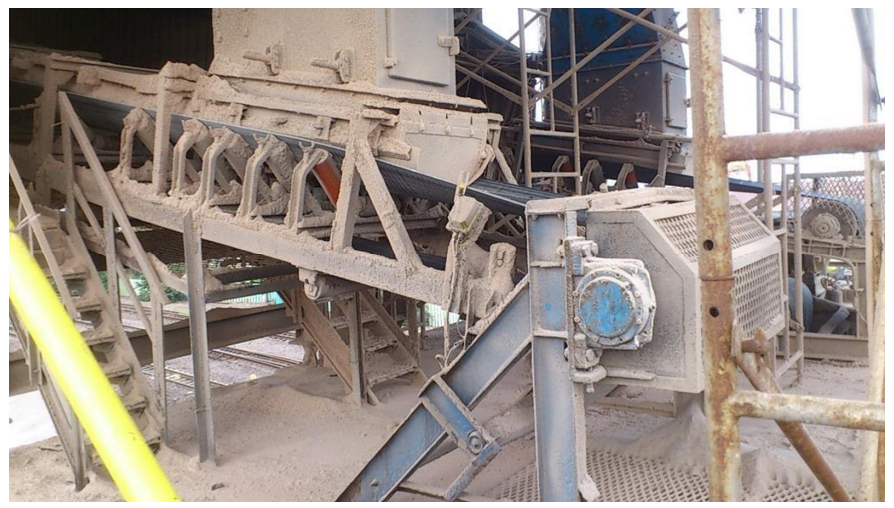

Figura 6: Acúmulo de fertilizantes nos equipamentos

O líquido liberado pela reação dos compostos do fertilizante com a umidade e a maresia acelerou a degradação de grande parte das vigas e pilares que compõem a estrutura. A resistência estrutural do concreto presente na estrutura era 
da ordem de 15 a $18 \mathrm{MPa}$. Desplacamento de concreto, armaduras expostas, redução da seção de peças estruturais devido ao adiantado estado de corrosão eram alguns dos sintomas da precariedade das peças estruturais da torre. (Figura 7).

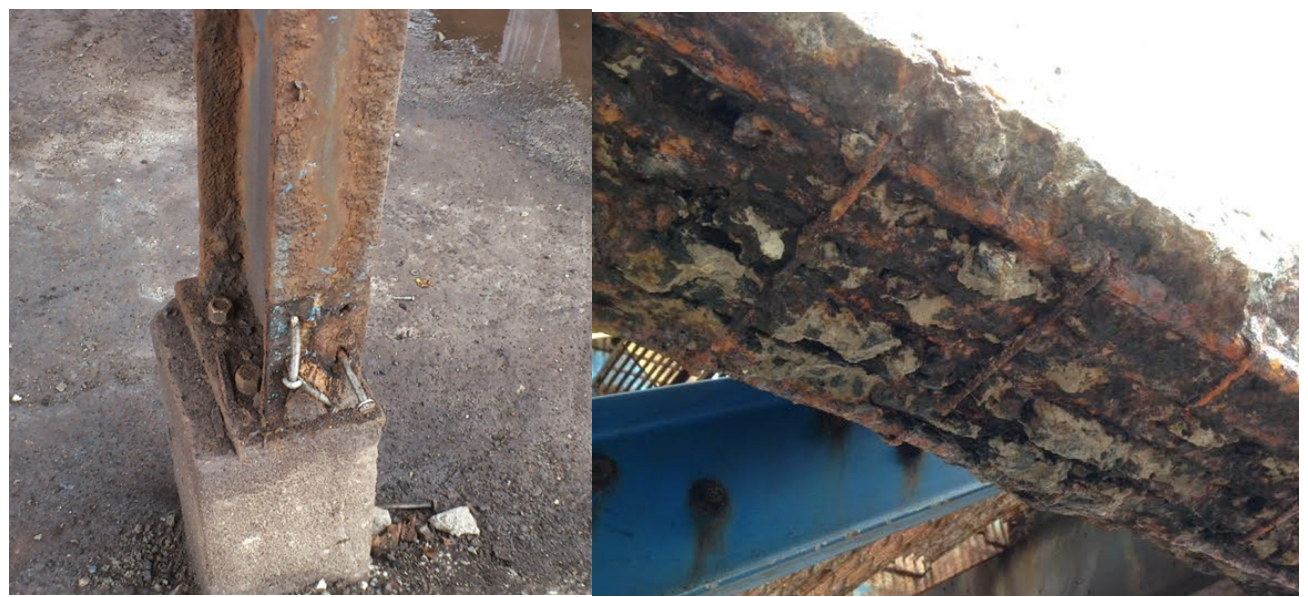

Figura 7: Pilar metálico e viga em concreto armado deteriorados

A lesão mais frequente identificada na edificação foi a desagregação. Pode-se dizer que existiam diversas origens para essa manifestação patológica, por isso cada caso foi analisado em particular a fim de se aplicar a correta reparação. $\mathrm{O}$ diagnóstico em relação às causas e origens dessas manifestações patológicas foi obtido pelo alinhamento dos levantamentos em campo (vistorias) e a experiência de um especialista contratado.

Na maioria das vezes, a desagregação é causada pela corrosão das armaduras do concreto. O óxido expandido pode aumentar de 8 a 10 vezes o volume original da armadura. Dessa forma são criadas fortes tensões no concreto, fazendo com que esse se rompa por tração. As fissuras tendem a seguir a linha das armaduras principais, podendo se manifestar inclusive na linha dos estribos se a corrosão for muito intensa.

Foi contabilizada, principalmente nos pilares e vigas, uma grande quantidade de corrosão e, consequentemente, fissuração, desagregação e exposição da armadura. Dessa forma, a seção dos elementos estruturais teve significativa redução, o que requereu uma intervenção mais incisiva nesses elementos.

As manifestações patológicas observadas, se não passassem por intervenções corretas, poderiam colocar em risco a estabilidade e segurança da edificação. As armaduras expostas nos pilares, vigas e lajes causavam preocupação e necessitavam de reparos imediatos.

\subsection{Análise das manifestações patológicas}

Nessa edificação, as manifestações patológicas foram analisadas de acordo com seu grau de severidade no elemento, sendo Superficial (S), Média (M) ou Profunda (P), tendo sido adotados os seguintes critérios:

- Concreto desplacado: O desplacamento do concreto caracteriza-se pelo lascamento ou esfoliação originados por esforços, interno ou externo, superiores às condições de resistência do material.

Causas: De origem interna provindas de reações de seus compostos e corrosão das armaduras.

Níveis de Alerta:

- SUPERFICIAL: desagregação atingindo apenas a argamassa superficial;

- MÉDIA: desagregação com o aparecimento dos agregados graúdos, sem atingir a armadura;

- PROFUNDA: desagregação com desprendimentos atingindo toda a espessura de cobrimento.

- Erosão do concreto: É o fenômeno de desintegração progressiva do concreto por ação de abrasão e/ou de lixiviação e/ou ataques químicos.

Causas: Desgaste da superfície devido ao atrito provocado por partículas transportadas pela água em movimento e pela lixiviação e ataque de agentes químicos corrosivos, principalmente se a superfície de concreto apresentar um grau insuficiente de compacidade (alta porosidade).

Níveis de Alerta:

- SUPERFICIAL: erosão com perda parcial do cobrimento do concreto, sem exposição dos agregados graúdos;

- MÉDIA: erosão com o aparecimento dos agregados graúdos, sem exposição da armadura;

- PROFUNDA: erosão com perda total de cobrimento e exposição da armadura. 
- Carbonatação: É a reação entre o dióxido de carbono $\left(\mathrm{CO}_{2}\right)$ do ar e o hidróxido de cálcio resultantes da hidratação do cimento, produzindo o carbonato de cálcio.

- Causas: Ocorre com a penetração de $\mathrm{CO}_{2}$, proveniente do ar, no concreto, quando esse é permeável, poroso, ou se apresenta com a superfície fissurada ou com segregação.

- Níveis de Alerta:

SUPERFICIAL: carbonatação cuja profundidade média é menor do que $5 \mathrm{~mm}$, há presença de eflorescência notadamente localizada na superfície do concreto;

MÉDIA: carbonatação cuja profundidade média é menor do que a espessura de cobrimento da armadura, sem despassivação da mesma;

PROFUNDA: carbonatação cuja profundidade média é igual ou maior do que a espessura de cobrimento da armadura com despassivação da mesma, acompanhada de mancha marrom-vermelho-acastanhada, originária provavelmente de corrosão da armadura no seu interior.

- Armadura expostas em processo de corrosão: Por se encontrarem indevidamente protegidas, ocorre o processo de corrosão do aço.

- Causas: Cobrimento insuficiente da armadura; concreto poroso; fissuração do concreto; ataque externo de cloretos e outros agentes químicos;

- Níveis de Alerta:

SUPERFICIAL: armaduras expostas não corroídas ou com corrosão atingindo o estágio de simples formação de película de oxido;

MÉDIA: para o caso de peças de concreto armado, com corrosão apresentando área da seção transversal da barra de armadura reduzida em até $20 \%$ da seção nominal;

PROFUNDA: Para o caso de peças de concreto armado cuja corrosão propicia redução da área da seção transversal da barra de armadura em mais do que $20 \%$ da seção nominal.

- Umidade/ infiltração: Qualquer ocorrência de passagem ou impregnação de água junto a poros do concreto.

- Causas: Infiltrações provenientes de água de chuva, por falha nos sistemas de drenagem.

- Níveis de Alerta:

SUPERFICIAL: água originada de infiltração, impregnada nos poros do concreto saturado, representada pela formação de manchas escuras nas superfícies;

MÉDIA: gotejamento originado de infiltração, com água impregnada nos poros do concreto saturado, num volume superior à capacidade de retenção do mesmo, provocando uma saída em forma de pingos;

PROFUNDA: surgência de água originada de infiltração passando pelos poros, fissuras ou aberturas da superfície do concreto, em vazão tal que promove a sua saída em forma de veios.

- Impermeabilização: Quando há deficiência de estanqueidade tem-se caracterizada uma falha de desempenho podendo-se comprometer o funcionamento e a durabilidade dos elementos estruturais.

- Causas: Essa anomalia pode ter incidência em sistemas de impermeabilização tanto internos como externos, podendo provocar o aparecimento de manchas nas superfícies, carbonatação, corrosão das armaduras, infiltrações e vazamentos de água.

- Níveis de Alerta:

SUPERFICIAL: danos apenas na camada de proteção mecânica sem o aparecimento de manchas de umidade na face oposta do elemento estrutural;

MÉDIA: danos da camada de proteção mecânica com o aparecimento de manchas de umidade na face oposta do elemento estrutural;

PROFUNDA: danos na camada de proteção mecânica com gotejamento de água na face oposta do elemento estrutural.

\section{RESULTADOS}

$\mathrm{Na}$ Tabela 1, encontra-se a relação das manifestações patológicas evidenciadas na edificação, mostrando-se o número de ocorrências das mesmas.

Tabela 1 - Manifestações patológicas da edificação

\begin{tabular}{|c|c|c|c|c|c|c|c|c|c|c|c|c|c|c|c|c|c|}
\hline \multicolumn{3}{|c|}{ Desplacamento } & \multicolumn{3}{|c|}{ Erosão } & \multicolumn{3}{|c|}{ Carbonatação } & \multicolumn{3}{|c|}{ Armadura exposta } & \multicolumn{3}{|c|}{ Umidade/Infiltração } & \multicolumn{3}{|c|}{ Impermeabilização } \\
\hline$S$ & $\mathrm{M}$ & $\mathrm{P}$ & $S$ & $\mathbf{M}$ & $\mathrm{P}$ & $S$ & $\mathrm{M}$ & $\mathrm{P}$ & $S$ & $\mathrm{M}$ & $\mathrm{P}$ & $S$ & $\mathrm{M}$ & $P$ & $S$ & $\mathrm{M}$ & $\mathrm{P}$ \\
\hline 11 & 11 & 15 & 0 & 5 & 0 & 0 & 2 & 1 & 0 & 1 & 13 & 0 & 1 & 3 & 0 & 0 & 0 \\
\hline \multicolumn{3}{|c|}{37} & \multicolumn{3}{|c|}{5} & \multicolumn{3}{|c|}{3} & \multicolumn{3}{|c|}{14} & \multicolumn{3}{|c|}{4} & \multicolumn{3}{|c|}{ 0 } \\
\hline
\end{tabular}

\subsection{Recuperação dos elementos estruturais em concreto armado}


A recuperação dos elementos estruturais consistiu no reestabelecimento à condição original das peças que se encontravam deterioradas por alguma manifestação patológica, ou seja, que apresentavam fissuras e/ou corrosão da armadura. Dessa forma, para recomposição da estrutura da edificação em estudo, em 2015, foram realizados os procedimentos a seguir.

\section{a) Limpeza dos elementos estruturais}

Consistiu na limpeza por hidrojateamento (Figura 8) para eliminar produtos impregnados na superfície do concreto, tais como fertilizantes, manchas de infiltração, e ainda auxiliar na identificação das áreas que deveriam receber os tratamentos específicos.

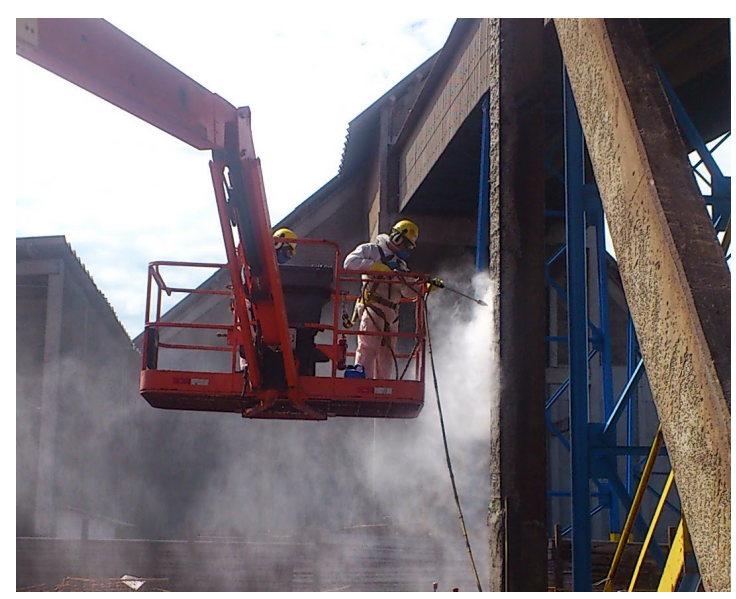

Figura 8: Limpeza dos elementos estruturais

\section{b) Identificação dos elementos estruturais comprometidos}

Todas as regiões que apresentassem anomalias tais como exposição e corrosão das armaduras, desagregação do concreto, segregação e fissuras que acompanhassem a projeção das armaduras, indicando sua corrosão, deveriam ser tratadas de acordo com as especificações.

b.1) Realização do mapeamento de anomalias e demarcação das regiões de reparo

Foram realizados mapeamentos e inspeções das estruturas com situação estrutural danificada. Também, foram feitos testes à percussão, com martelo geólogo (ponta viva), nas adjacências das áreas indicadas nos desenhos de mapeamento de anomalias, para identificar áreas nas quais o concreto poderia conter falhas ou vazios não identificáveis visualmente e delimitar as regiões a serem tratadas (Figura 9).

Toda superfície que apresentasse som cavo quando da auscultação percussiva foi demarcada. Para isso, circunscreveuse com lápis estaca as regiões que receberiam os tratamentos específicos de maneira a formar figuras geométricas regulares, evitando o excesso de arestas.

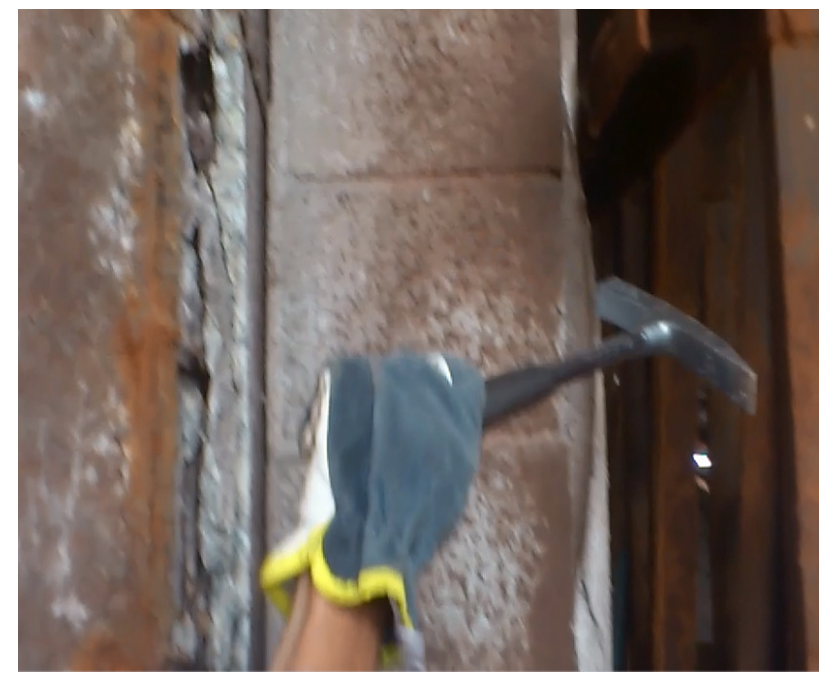

Figura 9: Inspeção com martelo geólogo

b.1) Demolição superficial e escarificação do concreto 
Utilizando marteletes pneumáticos leves (6 a $10 \mathrm{~kg}$ ), retirou-se o concreto de cobrimento das áreas demarcadas, até que fosse possível visualizar as barras de aço e passar a mão por trás da armadura. As regiões a serem tratadas deveriam compreender, além do trecho que apresentasse a corrosão, mais 5,0 a 10,0 cm de barra sã em cada extremidade das armaduras (Figura 10).

A escarificação da região a ser reparada deveria ser executada com a utilização de rebarbadores elétricos dotados de ponteiro com a extremidade em forma de picador ou xis superposto em cruz, ou ainda, ferramentas manuais como ponteiros, talhadeiras e marretas leves $(1 \mathrm{~kg})$, ou, nos casos de espessuras de remoção da ordem de 2 a $3 \mathrm{~mm}$, com percussão de martelo geólogo.

Essa atividade teve por finalidade retirar todos os materiais soltos, segregados, além do concreto existente no entorno das armaduras, e também criar uma superfície ideal para a aderência do material de recomposição.

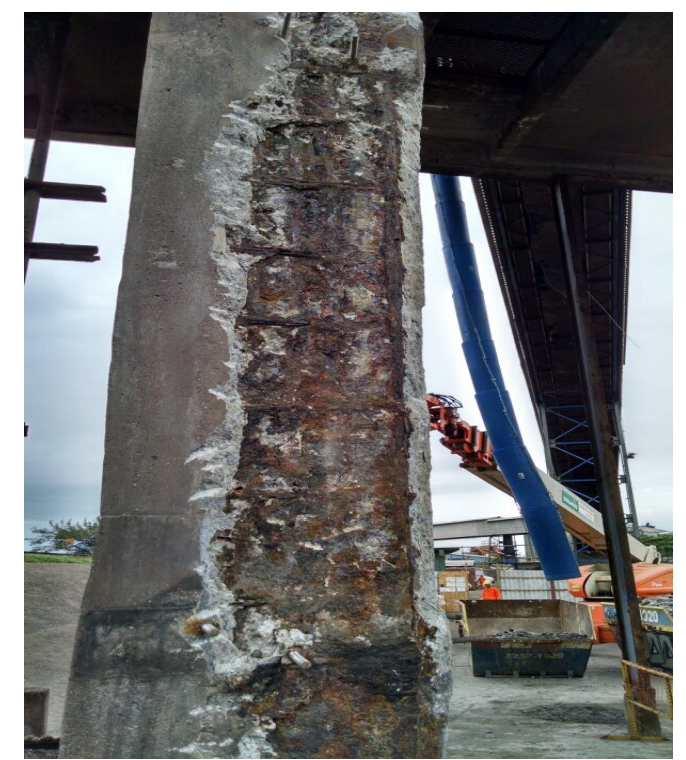

Figura 10: Demolição de concreto de cobrimento

\section{c) Limpeza das armaduras}

Todas as barras foram tratadas de maneira a retirar os produtos de corrosão, com auxílio de jateamento abrasivo com escória de cobre ou granalha de ferro, realizado com sistema pneumático e filtros, acompanhado de rodízios magnéticos que permitissem a coleta do pó. Ao final do jateamento, foi realizada criteriosa inspeção visual para avaliar possíveis pontos que não se apresentassem totalmente livres de carepas ou ainda que tivessem perda de seção transversal superior a $20 \%$ de seu diâmetro original (Figura 11).

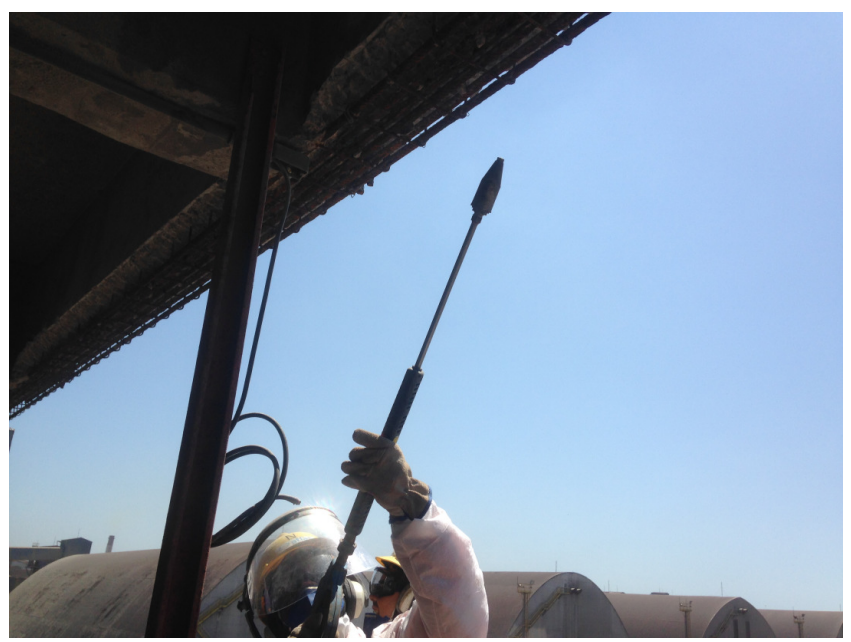

Figura 11: Limpeza das armaduras

\section{d) Substituição das armaduras}


Após a limpeza das armaduras, foi aplicado um revestimento de proteção contra a corrosão de base mineral e monocomponente, em duas demãos, com um tempo de secagem entre as camadas de aproximadamente 3 horas (Figura 12). O sistema de proteção deveria possuir certificado de teste que atestasse sua eficácia como proteção contra corrosão, após ser sucessivamente submetido ao teste com água destilada de acordo com a norma DIN 50017 (1982) (10 ciclos) e teste de névoa salina de acordo com a norma DIN 50021 (1988) (5 dias). O produto protetor anticorrosivo para a armadura aplicado foi o ZENTRIFIX KMH, que é um revestimento mineral utilizado como ponte de aderência e proteção anticorrosiva para reparos em concreto.

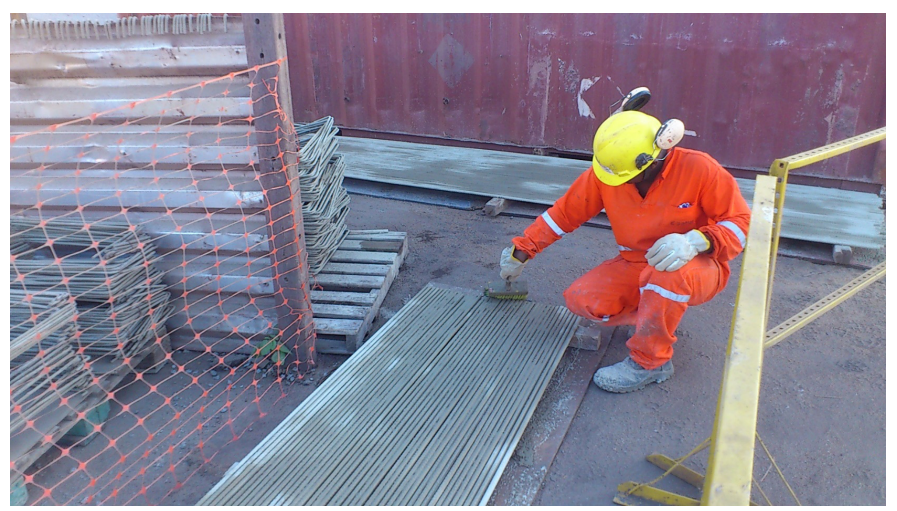

Figura 12: Aplicação da proteção à armadura

Caso fosse constatada a perda de seção por corrosão superior a $20 \%$ de seu diâmetro original ou seccionamento de barras, procedia-se com a substituição das armaduras utilizando-se transpasse, solda ou luvas rosqueáveis. Cada nova barra deveria ter as mesmas características da existente quando sã. A escolha da solução mais adequada deveria ser feita no momento da recuperação, avaliando-se a situação e a posição, entre outros fatores. Na Figura 13 apresenta-se a face inferior de uma viga de concreto armado com a armadura substituída, devidamente preparada.

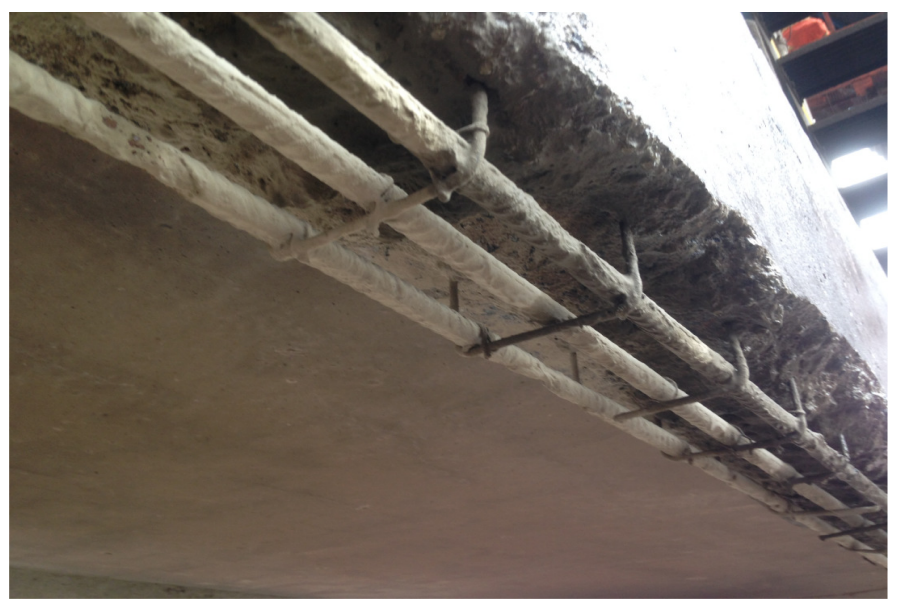

Figura 13: Substituição de armaduras deterioradas

\section{e) Recomposição dos pontos}

Nas áreas onde a profundidade da recuperação era inferior a $50 \mathrm{~mm}$, o material utilizado foi a argamassa polimérica com propriedades tixotrópicas, com resistência característica à compressão aos 28 dias de no mínimo 40 MPa. Foi utilizado o ZENTRIFIX CR, que é uma argamassa polimérica monocomponente indicada para reparos em concreto com agente adesivo integrado (Figura 14).

Para as áreas com profundidade de reparo superir a $50 \mathrm{~mm}$ ou arestas (cantos vivos), utilizou-se EMCEKRETE 50, um microconcreto à base de cimento Portland, com agregados naturais e aditivos, isentos de cloretos e componentes metálicos, autonivelante e apresentando resistência característica à compressão aos 28 dias de no mínimo $40 \mathrm{MPa}$ (Figura 15).

As subetapas dessa atividade foram as seguintes:

e.1) Ponte de aderência: Em virtude da presença de contaminantes a base de óleo mineral no substrato, foi necessária a aplicação de uma ponte de aderência especial constituída por primer epoxídico MC-DUR 1365 HBF desenvolvido para aplicação em substratos contaminados. 
e.2) Aplicação da argamassa: A argamassa de reparo foi aplicada sobre a ponte de aderência ainda fresca, ou seja, substância úmida sobre outra úmida, em uma camada com espessura mínima de $25 \mathrm{~mm}$ e máxima de $50 \mathrm{~mm}$.

e.3) Aplicação do microconcreto: O microconcreto de recomposição, por ser autonivelante, foi lançado em forma de madeira compensada, dotada de cachimbo, aplicando-se desmoldante para facilitar sua retirada. As formas foram devidamente calafetadas para evitar a perda de material e irregularidades na superfície da peça estrutural, recomendando-se o uso de espaçadores plásticos de modo a garantir o cobrimento necessário. Verteu-se ininterruptamente o graute até que o cachimbo fosse repleto do material.

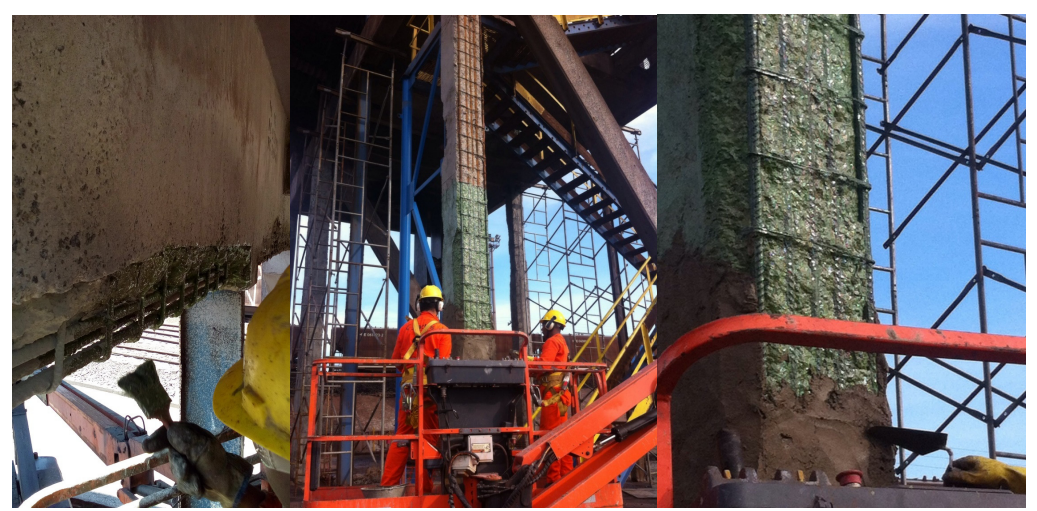

Figura 14: Aplicação de argamassa polimérica em pilar de concreto armado

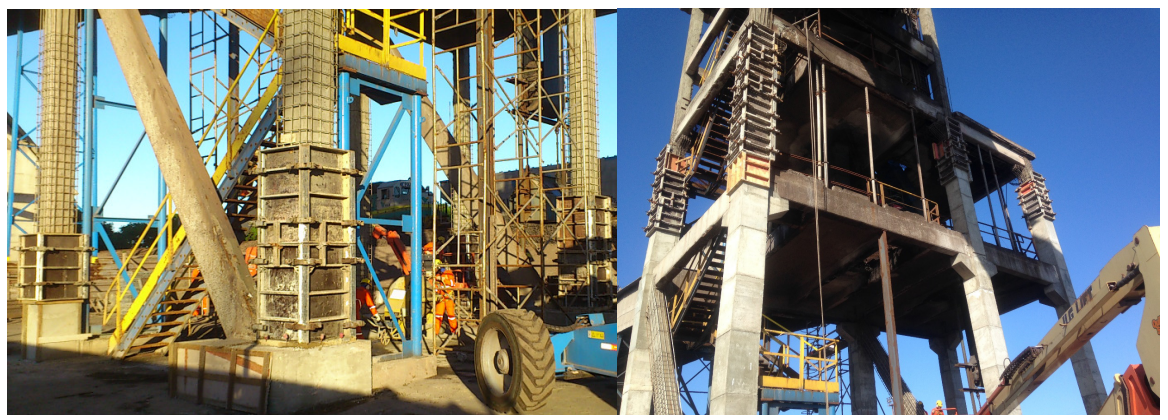

Figura 15: Aplicação de microconcreto em pilar de concreto armado

\section{f) Pintura}

Com o término das atividades de recuperação foi realizada a pintura de proteção à base de resina de poliuretano com alta resistência ao arranque e aberta à difusão do vapor de água, MC DUR 2496 CTP, com o objetivo de proteger a estrutura contra os agentes agressivos (Figura 16). A pintura apresenta características especiais para estruturas com ataque severo, como elevada resistência química e à abrasão, não é inflamável e proporciona facilidade de limpeza.
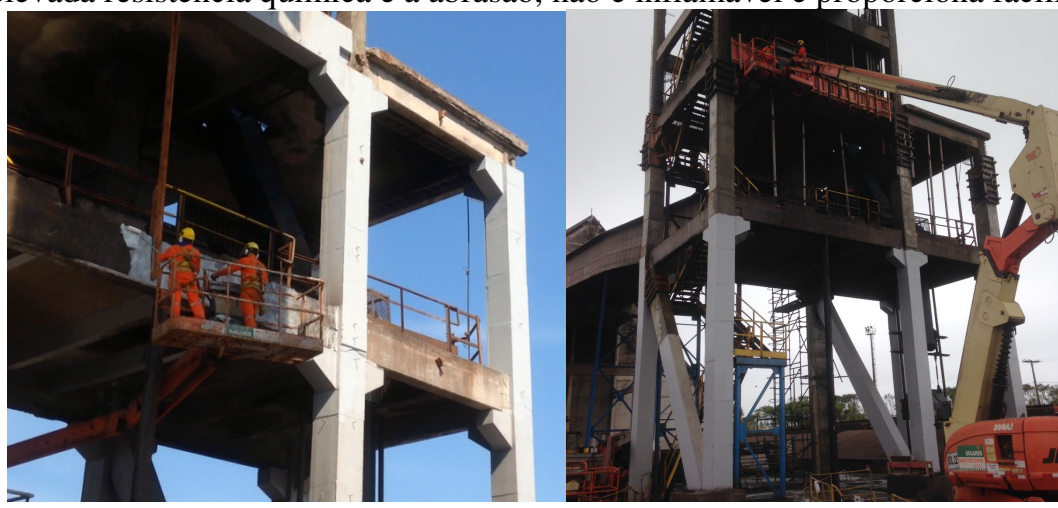

Figura 16: Pintura de proteção

\section{CONCLUSÃO}

Com base nas constatações visuais e nos resultados dos laudos de perícia, pode-se verificar que a corrosão encontrada nas estruturas da edificação foi oriunda da redução da alcalinidade do meio e, consequentemente, da perda da película passivadora (protetora). A despassivação das armaduras deve-se essencialmente à elevada temperatura, exposição das 
armaduras a ação do dióxido de carbono $\left(\mathrm{CO}_{2}\right)$ e de íons cloreto presentes na atmosfera, visto que o local está inserido em atmosfera marinha de alta agressividade. Essa frente de carbonatação avançada, porém, normal para a idade da torre, atingiu as armaduras, despassivando-as e dando início ao elevado processo corrosivo instalado nas estruturas.

Esse fenômeno relacionando a permeabilidade aos gases e, tendo em vista que os concretos adotados, quando da execução da construção da torre, possuem historicamente resistência à compressão em torno de 15 a 18 MPa (concretos mais porosos), facilitou o avanço da frente de carbonatação e a instalação do processo de corrosão.

A todos esses fatos citados adicionam-se os seguintes elementos como agravantes do processo corrosivo: baixa espessura de recobrimento das armaduras; elevada umidade relativa do ar (média de $70 \%$ ); temperatura média em torno de $27^{\circ} \mathrm{C}$; atmosfera marinha, onde há presença de cloretos; infiltrações oriundas de acúmulo de água pluvial; ausência, de sistema de inspeção/manutenção apropriado.

Foram apresentadas neste trabalho as medidas para correção e mitigação das manifestações patológicas que, em alguns casos, promoveram deterioração avançada nas estruturas de concreto armado da edificação, sujeita a ambiente agressivo quanto à corrosão. Destaca-se, então, a importância e necessidade de se manter um programa contínuo e adequado de recuperação de elementos estruturais sob condições severas de agressividade ambiental para evitar o seu colapso.

\section{AGRADECIMENTOS}

O presente trabalho foi realizado com apoio da Universidade Federal de Ouro Preto.

\section{REFERÊNCIAS}

ASSOCIAÇÃO BRASILEIRA DE NORMAS TÉCNICAS (ABNT). NBR 6118: Projeto de estrututras de concreto. Rio de Janeiro, 2014.

ASSOCIAÇÃO BRASILEIRA DE NORMAS TÉCNICAS (ABNT). NBR 8094: Material metálico revestido e não revestido - corrosão por exposição à névoa salina: método de ensaio. Rio de Janeiro, 1983.

CÂNDIDO, L. C. Patologias em estruturas metálicas. Ouro Preto: UFOP. 2005.

CASCUDO, O. O controle da corrosão de armaduras em concreto: inspeção e técnicas eletroquímicas. Ed. Pini. São Paulo. Ed. UFG, 1997.

DEUTCHES INSTITUT FÜR NORMUNG E. V. DIN 50017. Atmospheres and their technical application; Condensation water test atmospheres. Germany, 1982.

DEUTCHES INSTITUT FÜR NORMUNG E. V. DIN 50021. Spray tests with different sodium chloride solutions. Germany, 1988.

FERREIRA, R.B. Influência das adições minerais nas características do concreto de cobrimento e seu efeito na corrosão de armadura induzida por cloretos. 2003. Dissertação de mestrado - Curso de Mestrado da Escola de Engenharia Civil, Universidade Federal de Goiás, Goiânia, 2003.

GENTIL, V. Corrosão. 5. ed. Rio de Janeiro: LTC - Livros Técnicos e Científicos. Editora S.A., 2007.

HELENE, P. R. L. Corrosão em armaduras para concreto armado. São Paulo: Editora Pini - Inst ituto de pesquisas Tecnológicas IPT, 1986. 